\title{
Música y narrativa: \\ Vasos vinculantes en la construcción del sujeto lector
}

\author{
Music and narrative: \\ linking vessels in the construction of a subject reader
}

Milena Díaz Melgarejo*

Somos criaturas musicales de forma innata desde lo más profundo de nuestra naturaleza

Stefan Koelsch

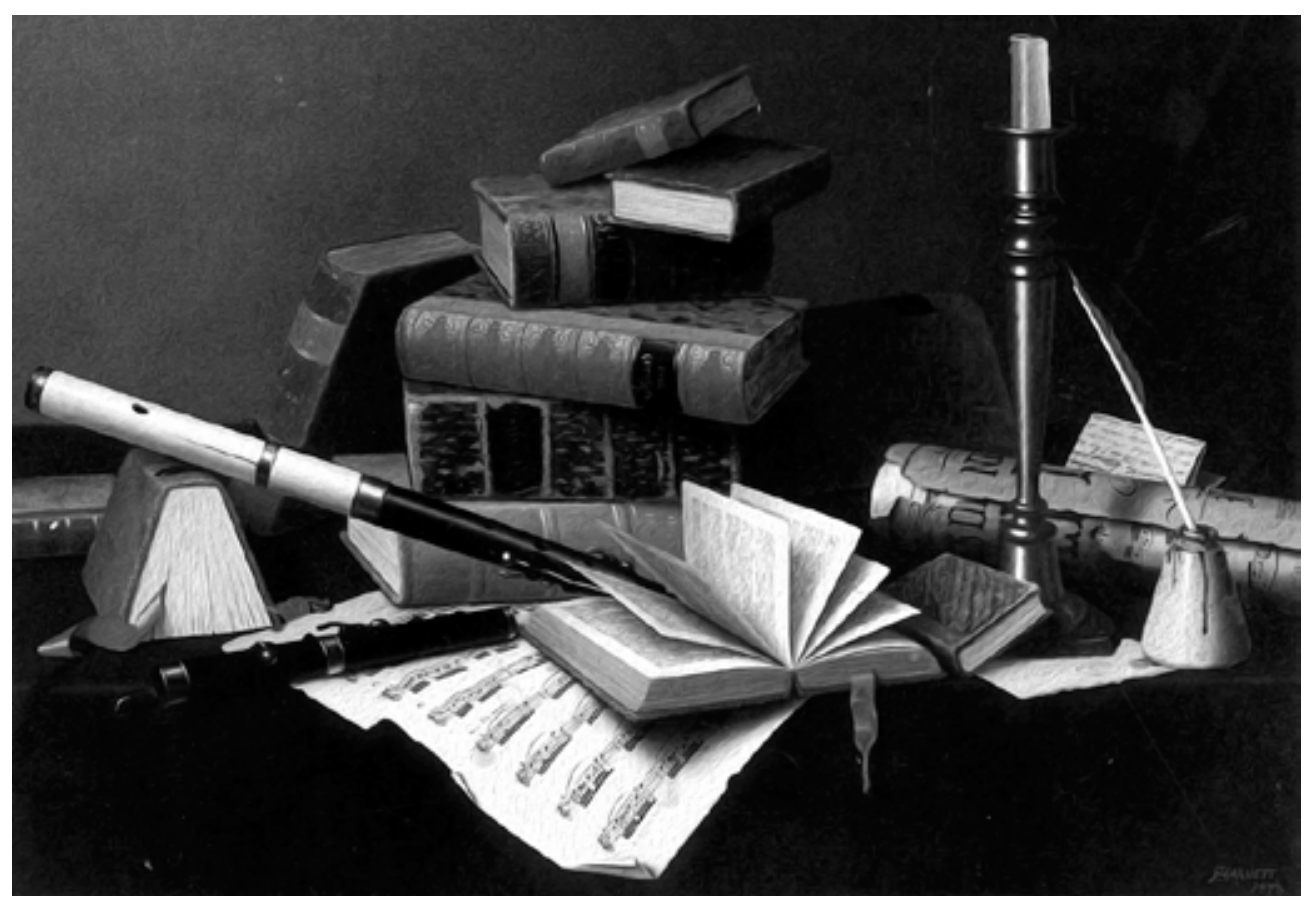

Citar este artículo como: Díaz, M. (2016). Música y narrativa: Vasos vinculantes en la construcción del sujeto lector. Revista Papeles, 8(16), 41-50.

Fecha de recibido: octubre 5 de 2015.

Fecha de aceptación: marzo 15 de 2016.

* $\quad$ MA en Ciencias de la Educación de la Universidad de San Buenaventura. Especialista en Didácticas para Lecturas y Escrituras con Énfasis en Literatura de la misma universidad. Licenciada en Español y Lenguas Extranjeras de la Universidad Pedagógica Nacional. Docente de Español y Literatura del Colegio Gimnasio los Portales. Bailarina del grupo de Salsa Clave y Fusión UPN. Se ha desempeñado como clarinetista en distintas Bandas Sinfónicas. Combina sus habilidades lingüísticas con la magia de la música, por ello su trabajo sobre los textos asume amuletos entre la semántica de la palabra y la sintaxis del pentagrama. Correo electrónico: clarinetango@hotmail.com 


\title{
Resumen
}

Este artículo presenta una reflexión en torno al vínculo existente entre música y narración. Recorrido que desemboca en una propuesta de aplicación en el aula, estrategia de apoyo que toma como base estos dos saberes para lograr un lector más competente. Se pretende analizar el efecto que la música tiene en el cerebro y sus múltiples posibilidades, las cuales, al ser compartidas con la literatura, favorecen el desarrollo cognitivo en pro de una óptima comprensión textual. Una consciencia de la búsqueda interdisciplinar en la praxis, un vínculo eficaz de los saberes encaminados hacia objetivos concretos que promuevan la construcción y aprendizaje del conocimiento son los pilares que enmarcan las líneas de escritura aquí sembradas.

Palabras clave: música, narrativa, estrategia, habilidades cognitivas, comprensión textual.

\begin{abstract}
The present article offers a deep reflection upon the link between music and narrative through a path which leads to a classroom strategy which takes into consideration these disciplines to make a reader more competent. It also intends to analyze the effect that music has in the brain as well as its multiple possibilities may be shared with literature, which benefit the cognitive development in order to achieve an optimal reading comprehension. Aims to achieve a true consciousness, regarding an interdisciplinary search in the practice and an effective link between knowledge areas, heading toward specific objectives which foster the construction and learning of the knowledge are, undoubtedly, the foundations that frame the ideas spread in this article.
\end{abstract}

Keywords: music, narrative, strategy, cognitive skills, reading comprehension.

\section{A modo de introducción}

$\mathrm{Al}$ pensar en la importancia y trascendencia que tiene la música en la vida del ser humano, recordamos expresiones tan famosas como la de Nietzsche al decir que sin ella la vida sería un error. Una mirada a nuestra cotidianidad nos da la evidencia de que la música es una compañera constante, una forma inherente al ser humano y a la vida misma; sustancia del lenguaje que nos constituye como sujetos de un mundo, o varios mundos del mundo.

Es conocida para nuestra historia la forma en que la música ha tomado protagonismo en la creación y fundación de los pueblos como elemento de supervivencia e identidad, y es posible ubicarla en un paralelo similar al de la lengua, en una interrelación, dos vasos vinculantes que heredan huella y tradición en el desarrollo de nuestra especie. De este modo, el habla se constituye como música dotada de significado, la palabra cobra forma a través de los sonidos de la voz, la música ha sido el vehículo perfecto que evidencia cómo la oralidad ha traído ríos de imágenes cotidianas de nuestros pueblos. Música y narración constituyen una dualidad perfecta, manifestaciones del lenguaje por excelencia.

Los sentidos nos permiten percibir el mundo y dotarlo de sentido, construimos nuestra realidad con base en aquello que se muestra ante ellos, y formamos juicios que van tomando forma de conciencia. De este modo, la música y lo que se cuenta en su compañía 
contribuye a la razón humana en su búsqueda de criterios, orden de pensamientos y actuar consecuente.

Todo lo anterior nos conduce a una bella posibilidad para aquellos que hacemos del lenguaje nuestra forma de servicio. Para los maestros, una luz al camino de la cognición y el desarrollo de habilidades desde la esencia del ser humano.
La música y lo que se cuenta en su compañía contribuye a la razón humana en su búsqueda de criterios, orden de pensamientos y actuar consecuente.

\section{Nuestra naturaleza musical}

La música se encuentra presente en nuestras vidas y tiene su origen a partir de la manifestación sonora del entorno y la elaboración intencional humana. En un principio se presenta la voz humana como su primera herramienta sonora, cuya función constituye un puente con el mundo. El individuo primitivo de un pueblo no diferencia su entorno, pensamientos y acciones, sencillamente se encuentra en el mundo, el cual explica como obra de seres invisibles, los cuales siente que debe tener de su lado o defenderse. De este modo, usa la voz como mecanismo de conjuro en favor de sus actividades cotidianas - conjuración melopeica-, acción que se transforma en cantos hipnóticos. Estas acciones, claramente diferenciadas en todas las culturas, constituyen las primeras construcciones

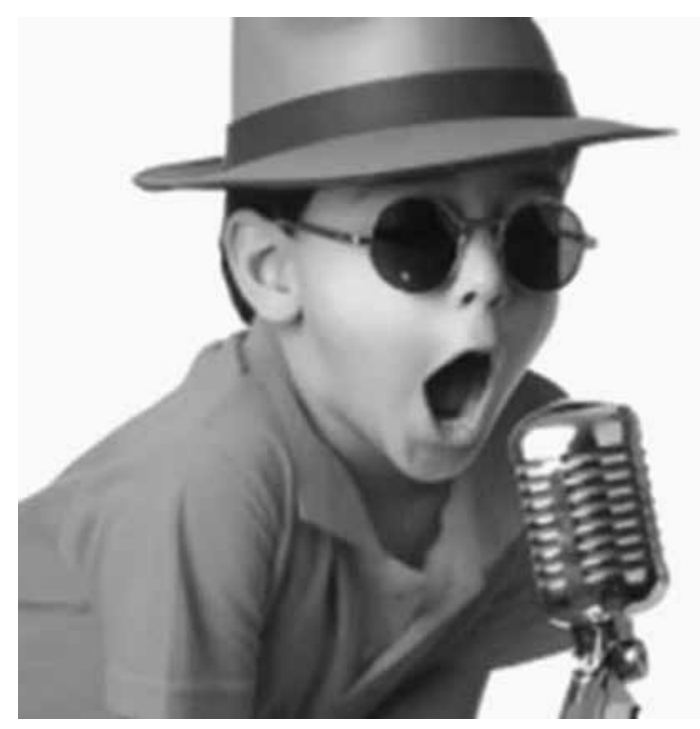

melódicas y rítmicas (Honolka, Richter, Nettl, Stäblein, Reinhard y Engel, 1998).

Por otra parte, Stefan Koelsch, músico, maestro e investigador comprometido con la neurociencia, afirma la presencia innata de nuestra capacidad musical. En una entrevista conducida por Eduardo Punset para su programa REDES (2011), argumenta esta disposición innata con la forma como desarrollamos el habla al escuchar y comprender los sonidos de la lengua en conjunto con la emotividad producida en el cerebro al percibir elementos como el ritmo, tono, velocidad y melodía de la voz. Insiste por ello en la importancia del juego de entonación con los niños para el desarrollo del lenguaje, ya que diversos estudios muestran que los cantos de cuna y todos los juegos de entonación y modulación de la voz por parte de los padres, benefician en gran manera al bebé; y por el contrario, quienes no obtienen este beneficio, son más propensos a sufrir trastornos del lenguaje. Por otro lado, los avances científicos han hecho posible evidenciar la capacidad del neonato para detectar alteraciones en secuencias rítmicas, hallazgos que ponen de manifiesto nuestra naturaleza musical (Honing, 2011).

La música, tema apasionante que en fusión con la narrativa, brinda una amalgama de posibilidades didácticas dentro del aula de clase. En este sentido, la estrategia se convierte en el eje central del enfoque didáctico, propósito central del presente artículo. 


\section{Música y narración}

La canción ha sido el ejemplo por excelencia de esta relación música-narrativa. El ejercicio de contar cantando se remonta a nuestra historia, un hecho natural humano que cuenta con siglos de tradición y se actualiza hasta nuestra era confirmando la disposición musical como forma que acompaña y soporta los discursos que suenan por generaciones, creando de este modo patrones de memoria, estructuras o reestructuras de la realidad, referentes simbólicos que atestiguan la existencia del ser en el mundo y su complejidad. De este modo, los oyentes buscan complicidad, formas elaboradas que den cuenta de su humanidad y singularidad de vida. La canción lleva consigo la voz de los individuos, de los pueblos, de las cosas, de todo aquello que puede ser interpretado o imaginado en la finitud de la humanidad. La voz se nutre de historias, relatos que se actualizan en las voces de los tiempos:

Hoy, en pleno siglo veinte

nos siguen llegando rubios

Y les abrimos la casa

y les llamamos amigos.

Pero si llega cansado

un indio de andar la sierra

Lo humillamos y lo vemos

como extraño por su tierra.

Amparo Ochoa:

La maldición de la malinche (canción)

En esta búsqueda por las formas, la creatividad ha aflorado en múltiples posibilidades, donde no solo la música cobra protagonismo en sus infinitos caminos tonales, también la lengua, como materia comunicativa, ha sido aprovechada en el diseño de estructuras artísticas que juegan a anclarse en los sonidos instrumentales que acompañan las voces en el canto de manera literaria. Un bello ejemplo de ello es una canción del cantautor uruguayo Alfredo Zitarrosa, El violín de Becho, en el cual la metáfora y el sonido instrumental tejen una historia en un juego de palabras que dejan elementos implícitos que deben ser descifrados por un lector atento.

La arquitectura del texto entramado en estrategia, la emotividad de la voz que se refleja en un tono triste, trágico y melancólico en conjunto con el violín que acompaña con juego de registros en apoyo a lo que se enuncia en el texto constituyen un anclaje a la emotividad del lector y un puente en el desarrollo de habilidades cognitivas al incentivar su atención por el descubrimiento de la forma artística presentada. Es interesante también en este ejercicio de análisis percibir cómo las versiones de una misma canción promueven emociones $y$ afectos distintos, la presencia y ausencia de elementos determinan el impacto de la pieza; esto apoya la trascendencia de la música en nuestra recepción cerebral.

El uso de la metáfora, el juego entre lo dicho y no dicho trazan un margen especial en la forma de percibir estructuras estratégicamente elaboradas sobre aquellas que no cuentan con un reto cognitivo. A continuación un fragmento de la canción mencionada anteriormente:

Vida y muerte, violín, padre y madre

Canta el violín y Becho es el aire

Ya no puede tocar en la orquesta

Porque amar y cantar eso cuesta.

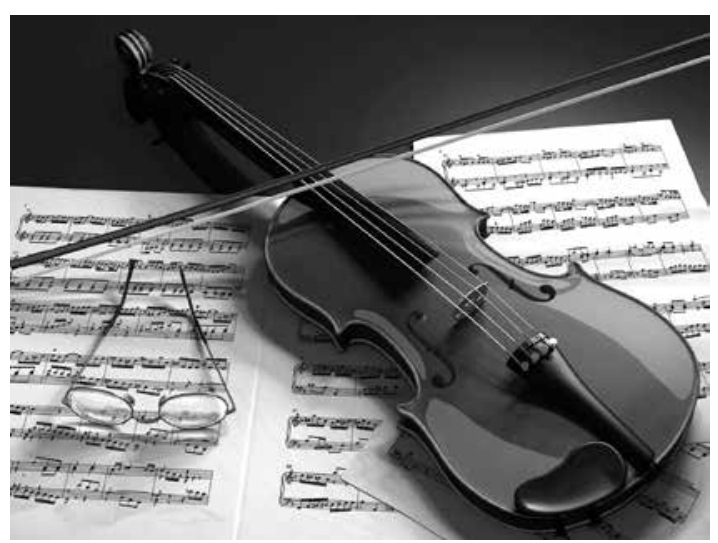




\section{Líneas orientadoras de estrategias:}

\section{El acto de lectura en la narración}

Manuel Alejandro Prada en su libro Lectura y Subjetividad afirma la importancia de la narración para la vida del ser humano, no solo por su posibilidad catártica, también por la capacidad de cuestionamiento ético frente a su realidad y tragedia cotidiana; en este sentido, la lectura se constituye en vehículo interpretativo entre la narración y el lector. Para esta idea se respalda en la hermenéutica de Paul Ricoeur y su fenomenología de la lectura, para definirla como un espacio de apropiación de la vida, una dialéctica de afirmación y oscurecimiento del sí. Con este propósito, Prada apoya la idea acerca de que la lectura debe ser un esfuerzo de configuración de sí mismo y del mundo, y que para ello el lector debe hacerse.

"Hacerse" implica un trabajo, un ejercicio, una puesta en escena permanente en la que la lectura no se me da como algo natural, sino que me exige una respuesta, me pide alguna responsabilidad. Además el reflexivo "hacer-se" da cuenta de que el trabajo de lectura recae sobre el que lee, no lo deja como estaba, lo transforma. (...) "hacerse lector" es "hacerse sujeto", no en un sentido trascendental, sino como sujeto encarnado, histórico (Prada, 2010, pp. 22-23).

Ahora bien, reconocemos la importancia de la narración literaria en su capacidad de crear mundos posibles a través de la ficción y su disposición de espacios para que el sujeto se confronte a través del ejercicio de la lectura. En relación con lo anterior, la idea de lectura debe constituirse en el puente por excelencia entre la emisión y la recepción de la narración. La excelencia se entiende, en este sentido, en concordancia con Prada, como un acto que requiere esfuerzo, preparación y formación, aun cuando la lectura implique la subjetividad del sujeto lector. El carácter subjetivo es orientado gracias a la comprensión del texto que brinda y desprende posibilidades interpretativas. Lo importante a resaltar es que este proceso va subordinado al trabajo de un lector competente. Esta perspectiva es importante para la objetividad de una didáctica de la lectura del texto literario, ya que permite al maestro orientar sus esfuerzos a lograr tal fin, la búsqueda de estrategias que potencien las habilidades lectoras para la comprensión e interpretación lectora en pro de un mejor placer estético, disfrute y aprovechamiento literario.

\section{Música, cerebro y emotividad}

Como maestros, es imprescindible conocer el funcionamiento del cerebro en sus distintas etapas. Este conocimiento nos permite la creación de estrategias que contribuyan a lograr el desarrollo de habilidades que conduzcan a la construcción del conocimiento. En este sentido, es importante recordar el concepto de plasticidad neuronal, capacidad que tiene el cerebro para modificar su estructura a partir de estímulos externos (Jäncke, 2009).

En una conferencia realizada en la ciudad de Medellín (2012), la neuróloga Luz Stella Caycedo afirma que el entorno y las experiencias determinan nuestro aprendizaje. Investigaciones realizadas por varios especialistas muestran que el cerebro requiere de patrones para entender y dar sentido al mundo. Todo el cerebro está comprometido con el análisis musical, los dos hemisferios se activan en este proceso, y por ello tiene la capacidad de crear recuerdos de distinta forma, porque logra tocar el núcleo de la actividad emocional, lo cual hace que el sonido se asocie a un pensamiento y adquiera sentido. "La música no es sólo una actividad artística, sino un lenguaje encaminado esencialmente a comunicar, evocar y reforzar diversas emociones" (Gómez, 2007, p. 39). 
De otra parte, la doctora afirma que algo maravilloso que también han descubierto los expertos es que la música, al ser interpretada, en el caso concreto de los instrumentistas, activa el cuerpo calloso del cerebro, parte que conecta los dos hemisferios permitiendo el trabajo conjunto y las destrezas de estas dos mitades. Metafóricamente es bello reconocer los puentes que la música puede crear, es en esta línea que ella puede aprovecharse como puente ideal para mejorar la capacidad de atención y los procesos de memoria, entre otras cosas, para la construcción del conocimiento.

El vínculo emocional que crea la música es un medio de comunicación tan universal como el lenguaje.

Sandra Trehub

\section{Propuesta didáctica}

Para ejemplificar una posible aplicación de este vínculo música-literatura, se ha tomado como texto base Fernando Furioso de Hiawyn Oram (1998), con actividades orientadas para niños de primero de primaria. El ingenio del cuento radica en la intención cognitiva de la estructura narrativa. Contiene una anécdota sencilla, común a cualquier infante: el enojo que produce la reprensión de una madre sobre un hecho cotidiano; no obstante, los diálogos y los sucesos llevan al pequeño lector a una dimensión de secuencias lógicas que van de lo micro a lo macro, estructura aprovechable para el estudio de las relaciones causales y espaciales dentro del armado textual de forma progresiva en una cadena escénica de espacios que van por niveles de amplitud. Ahora bien, recordemos que el fin radica en cómo utilizar la música para facilitar e incentivar en el niño la comprensión de estas estructuras dentro del texto a través de la experiencia musical para llegar a la deducción y construcción conceptual.

Es importante aclarar, para el caso de esta propuesta, que la música está en función de la narrativa, por cuanto el objetivo central es el hallazgo y uso de estructuras musicales en la narración como estrategia de apoyo para el desarrollo de habilidades cognitivas (atención y memoria) que fortalezcan la comprensión del texto literario: coherencia y cohesión: relación tiempo y espacio/causa y efecto en términos de relaciones (Van Dijk, 1980). Se dará prioridad y se tendrá como enfoque estas dos formas, lo cual no restringe la oportunidad de dar cuenta de otros aspectos presentes en la narración.

Es posible afirmar que detrás del texto escrito puede descubrirse una forma musical que fluye y se hace presente en la lectura en voz alta. Al revelar la intención de ese descubrimiento y tomar provecho de la riqueza musical en la relación de estos dos textos podría evidenciarse un avance en la habilidad lectora. Aunque la música interpretada con instrumentos acompaña y tiene un impacto especial en la recepción de la narración, es posible y se constituye en un reto formar la voz, como instrumento natural, para el ejercicio de lectura.

Aunque se trata de un libro-álbum, esta posible actividad va dirigida hacia el análisis del texto escrito. Las ilustraciones pueden ser una herramienta de apoyo con la intención de desarrollar trabajo cognitivo en el niño; no obstante, se insiste en que esta propuesta se enfoca solamente en el texto escrito y la vinculación musical. Una posible actividad a plantear sería la integración de la imagen con nuestra línea de estudio musical. 


\section{Ruta metodológica}

Lectura del cuento en voz alta: La lectura al ser agradable al oído y llevar consigo un ritmo adecuado, permitirá al niño aumentar la percepción de la misma ya que no solo escucha el hilo discursivo del cuento sino que percibe también la musicalidad, activando los procesos cerebrales que ayudarían a la comprensión del texto. Por esta razón la lectura en voz alta debe realizarse atendiendo objetivamente a este aspecto.

Se trata de hallar la forma rítmica de los enunciados. La organización sintáctica del texto tiene un propósito semántico, por ejemplo, algunas frases en el libro están fragmentas, lo cual marca una pausa entre ellas, y este aspecto debe reflejarse en la lectura en voz alta. La voz puede trabajarse como elemento sonoro y herramienta musical, de tal modo que logre conectar la emotividad del estudiante y ganar su atención, esto es posible gracias a la consciencia sobre los fenómenos suprasegmentales (acento, ritmo y entonación), término de la lingüística, cuya función contribuye a la construcción del sentido en los discursos. Por esta razón, la lectura no debe reducirse a pronunciar simplemente segmentos de la lengua, sino que estos, acompañados de un uso efectivo de elementos musicales naturales al habla, permitan dar personalidad al texto para llevar a los estudiantes a una mejor comprensión del mismo.

Por otra parte, es importante el tempo (tiempo musical, cadencia) en la lectura, revelado en aspectos como la duración silábica, el acento de las palabras y la modulación de la voz para dar sensaciones de inicio y final, pausas y demás elementos prosódicos que refuercen rasgos de intención en la lectura del texto.

Podemos hallar la relación entre la estructura del texto escrito y su forma musical, este último depende y se desprende del primero. La narración cuenta, nos transmite un sentido que se desenvuelve en una estructura de inicio, desarrollo y final. No obstante, en nuestro texto a tratar, esta estructura se mantiene pero con formas distintas, es decir, el inicio se encuentra en "Había una vez", pero simultáneamente es el conflicto mismo y el desenlace lo realiza el lector puesto que se trata de una pregunta. La música se mueve al compás del texto escrito, está a su servicio, nos envuelve en la trama, funciona como soporte emocional, es una silueta que nos acompaña en la estructura. Como mencionamos anteriormente, la voz sería en este caso el canal que nos permite percibirla y disfrutarla.

A continuación mostraremos los elementos musicales presentes en el texto de Fernando Furioso y su tratamiento en la deducción de los objetivos conceptuales propuestos:

El pie acentual como unidad rítmica: identificar las sílabas tónicas dentro de las frases, cada una constituye, en este caso, un grupo rítmico, delimitado en principio por pausas.

\section{Había una vez un niño llamado Fernando.}

Una noche, quiso quedarse despierto viendo (pausa semántica)

$$
\text { una película de vaqueros en la televisión. }
$$

Vemos aquí cómo podemos marcar un tempo, en este caso, pulsos de cinco tiempos para cada línea. Por supuesto no podemos reducir la lectura atendiendo mecánicamente a estos acentos, podemos hacer variaciones, el ejercicio está en aprovechar los acentos vocálicos,

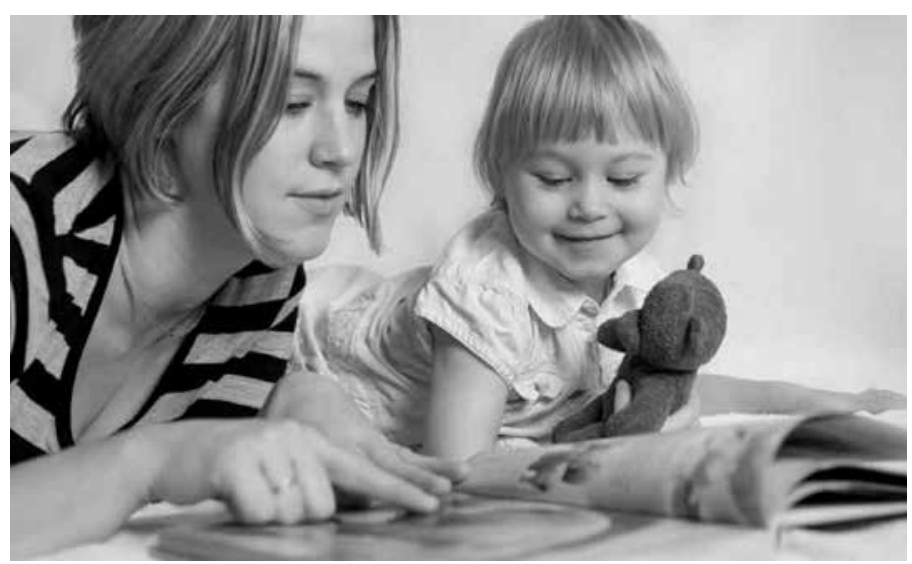


al igual que la duración de cada sílaba para enriquecer la entonación y potenciar la música en la lectura.

Juegos lingüísticos de repetición: este es otro elemento interesante que nos ofrece el texto y que resulta muy agradable al oído. Recordemos que la repetición e imitación nos lleva a activar mecanismos de memoria. Si el niño nos acompaña a completar frases del texto e imitarlas con un ritmo particular, aumentan los beneficios ya descritos. Investigaciones muestran que al oír, pero sobre todo al ejecutar ejercicios musicales, se activan todas las áreas del cerebro, hecho que nos permite predecir el éxito en la recepción y asimilación del cuento.

Ejemplo 1

-Me pondré furioso, - dijo Fernando.

-Ponte furioso, _dijo su mamá.

Ejemplo 2

$Y$ así fue. Se puso furioso. Muy muy furioso.

Tan furioso que su furia se convirtió en una nube tormentosa (...).

Aprovechamos este ejemplo para argumentar del mismo modo cómo los signos de puntuación nos permiten la construcción rítmica de la frase. La pausa semántica o por puntuación da tiempo al cerebro para procesar la información y prepara el oído para lo que continúa. También en este ejemplo podemos encontrar la riqueza de las curvas de entonación al hallar la inflexión tonal (acento de frase), también llamado contorno de entonación, como herramienta aprovechable en la lectura en voz alta:

$Y$ asífue. Se puso furioso. Muy muy furioso.

Ejemplo 3

La siguiente secuencia se repite como intermedio a lo largo de las distintas escenas del cuento. Cumple la función de reforzar una actitud y una acción dentro de la narración y nos deja una cadena de agentes del diálogo dentro de ella. En estructura, cumple la misma característica del coro dentro de las canciones. Además, nos agrega un elemento memorístico importante para nuestro ejercicio de secuencia: los turnos de habla de los personajes. $-Y a$ basta, dijo su mamá.

Pero no bastó.

-Ya basta, _dijo su papá.

Pero no bastó.

-Ya basta, -dijo su abuelo.

Pero no bastó.

-Ya basta, _dijo su abuela.

Pero no bastó.

Por otra parte, es preciso resaltar las onomatopeyas y signos como orientadores de una lectura más intencionada:

Que resquebrajó la superficie de la Tierra.

iiiCRAAAAAC!!! Sonó, como un gigante rompiendo un huevo.

Finalmente, y muy importante dentro de esta esfera de la entonación, se encuentra un elemento fundamental en la orientación musical dentro del texto narrativo: el tono, concepto que difiere de significado en la dimensión de la lengua (rasgo emotivo en la forma de enunciar: alegre, triste, melancólico, etc.), por lo cual al referir a esta última usamos el concepto de tonalidad, el cual indica la escala por la que se interpreta una pieza.

Las tonalidades musicales varían en su construcción a nivel de vibraciones de sonido, lo cual tiene un impacto en la emotividad de los oyentes. Un ejemplo concreto es la receptividad frente a escalas mayores y menores, las primeras más alegres, las segundas más tristes; efectos de percepción, no en todos los casos. El tono de la voz en la lectura causa efectos auditivos paralelos, es decir que el impacto y receptividad de la narración puede condicionarse por la esfera emotiva que emite la voz lectora, rasgo que puede convertirse en un pro o contra de acuerdo con la formación y compromiso vocal del lector. 
Luego de la experiencia con el texto, llegaremos a los conceptos concretos en narrativa que nos hemos propuesto, para los cuales la memoria tiene un papel importante.

\section{Fernando se sentó en un trozo de Marte y pensó} pensó y pensó.

¿Por qué fue que me puse tan furioso?

Pero no se pudo acordar.

\section{¿Y tú te acuerdas?}

El final del cuento deja al niño una pregunta que le obliga a volver al inicio de la narración. Aprovecharemos la secuencia del mismo para probar la memoria, y a su vez, llegar a los conceptos que queremos. Así que pedimos a los niños narrar los sucesos pero desde el último hasta el primero, invertimos el orden de la secuencia hasta llegar a la respuesta que se encuentra al inicio del cuento. Probablemente muchos la sepan de antemano, pero nuestra regla de juego es: "vamos a buscar o comprobar la respuesta devolviéndonos por la ruta de nuestro texto" y en este proceso de re-narración inversa, el niño pone en marcha la lógica, tanto de tiempo como de espacio narrativo, da cuenta de los procesos de memoria en el orden de los sucesos, efectúa la lógica de causa y efecto. En la re-narración el niño al realizar las conexiones proposicionales de manera oral requiere del uso de conectores distintos, de léxico adicional para hacerse entender, incluso el empleo de elementos no verbales, etc., evidencias que complementan nuestros conceptos de estudio y nos orientan para la construcción de otra estrategia.

Por otro lado, podemos invertir la lógica de nuestra experiencia musical, del oír al emitir. El niño al narrar expresa música de forma natural. Investigaciones muestran que hasta un promedio de cinco años de edad, las narraciones de los niños se asemejan naturalmente al canto porque conservan en su memoria las modulaciones de voz que ha realizado su madre, maestra o material sonoro al que ha estado expuesto, son más expresivos por el uso de onomatopeyas, exageración en el alargamiento de sílabas, etc. Algunos ejemplos son los trabajos propuestos por José Feu Guijarro (2008), y María Del Valle Abraham, Rosa María Brenca y Valeria Guaita (2009). Entonces, con parámetros similares, podemos realizar el registro y transcripción de las narraciones de los niños, no solo para dar cuenta de la comprensión lectora sino para analizar rasgos musicales presentes en su voz.

Esta narración nos ofrece un reto moral en cuanto que el niño puede cuestionar su propio actuar a través de un hecho cotidiano ficcionalizado y le deja una posibilidad de alteridad al analizar si realmente lo ocurrido a Fernando tenía tanta trascendencia. La hiperbolización de los sucesos le permite reflexionar al niño sobre la dimensión real de los problemas y manejo de sus emociones, además, la importancia de escuchar a otros y lo que puede causar el descontrol de sí mismo.

Infants can perceive basic aspects of temporal structure in music, but this ability is likely to undergo change with increasing exposure to music

Sandra E. Trehub, Erin E. Hannon

\section{Enlaces}

Por último, es propósito de este artículo nombrar tres referentes artísticos que pueden servir de apoyo en el objetivo de vincular música y narración en la búsqueda de estrategias para un lector más competente. Cabe destacar que en ello el cine se presenta como una elaboración magistral de este propósito. 
El baile (Le bal) de Ettore Scola, película italiana, la cual posee una estructura interesante, ya que la música se constituye en la base narrativa junto con el baile. En ella, el cómo se cuenta, traza una convergencia aprovechable para el desarrollo de destrezas cognitivas en el aula.

Melodía de la vida (Les uns et les autres) de Claude Lelouch, película francesa, cuya estrategia gira alrededor de una de las obras musicales más importantes de la historia: El Bolero de Ravel. Un homenaje a la música que a su vez sirve de forma para mostrar cuatro historias de manera polifónica que convergen e ilustran el transcurrir del tiempo europeo luego de la Segunda Guerra Mundial.

Llanto por Ignacio Sánchez Mejías, poema escrito por Federico García Lorca. Texto cuya estrategia reitera en la repetición de una frase mientras se teje la narración siempre atropellada por tal repetición, juego estratégico con la lengua que incentiva el desarrollo de habilidades de pensamiento para la comprensión lectora.

\section{Referencias}

Banai, K., \& Ahissar, M. (2013). "Musical experience, auditory perception and reading-related skills in children". Recuperado de: http:// journals.plos.org/plosone/article?id=10.1371/ journal.pone.0075876

Caycedo, Luz Stela (2012): "Cómo nace un sentimiento. Música y cerebro". Conferencia magistral Parque explora, Medellín, Colombia, 14 de noviembre de 2012.

Casanueva, M. (1994). "La huella del folclore en la Literatura Infantil". Recuperado de: http:// gredos.usal.es/jspui/bitstream/10366/69142/1/ La_huella_del_folclore_en_la_literatura_.pdf

Del Valle, M., Brenca, R. \& Guaita, V. (2009). "Las destrezas narrativas en niños de 5 años: Propuesta de un instrumento de evaluación clínica del lenguaje". Revista chilena de Fonoaudiología.

Feu, J, \& Piñero, DE. (2008). "Pasajes sonoros en la primera infancia: retrato musical de la narración infantil." Recuperado de: https:// magisteriomusicainfantil.wikispaces.com/file/ view/EU04303.pdf

Font, D., \& Cantero, F. (2008). "La melodía del habla: acento, ritmo y entonación". Recuperado de: http://www.grao.com/revistas/eufo nia/043-musica-y-lenguaje/la-melodia-delhabla-acento-ritmo-y-entonacion

Gallo, E., Reyzábal, M. \& Santiuste, M. (2008). Música y lingüística. INFAD. En: Revista de Psicología, pp. $315-323$.

Gómez, M. (2007). Música y neurología. Neurología, 22(1), 39-45.
Grahn, J. (2013). Music on the Brain. [video]. De: https://www.youtube.com/watch? $=\mathrm{u} 1 \mathrm{v}$ ITIOEsPk

G. Soria-Urios, et al. (2011). "Música y cerebro (II): evidencias cerebrales del entrenamiento musical." En: Revista Neurol, pp.739-746.

Honing, H. (2011). Listening to music. [video]. De: https://www.youtube.com/watch?v=EU7HcV 83RXc

Honolka, K., Richter, L., Nettl, P., Stäblein, B., Reinhard, K. y Engel, H. (1998). Historia de la música. Madrid, España: Editorial EDAF.

Jäncke, L. (2009). "Music drives brain plasticity". De: http://www.ncbi.nlm.nih.gov/pmc/articles/ PMC2948283/

Oram, H. (1998). Fernando furioso. Caracas: Ediciones Ekaré. Ilustraciones: Kitamura, S.

Prada, M. (2010). Lectura y Subjetividad. Una mirada desde la hermenéutica de Paul Ricoeur. Bogotá: Uniediciones - Grupo Editorial Ibañez.

Punset, E. (2011). Música, emociones y neurociencia. Programa redes. [video]. Disponible en: https://www.youtube.com/watch?v=skSAno ClGws

Trehub, S. (2006). "Infant music perception: Domain-general or domain-specific mechanisms?". Disponible en: https://faculty.unlv.edu/ ehannon/publications/Trehub_Hannon_2006. pdf

Van Dijk, T. (1980). Texto y contexto: Semántica y pragmática del discurso. Barcelona: Paidós. 